DOI 10.5216/ia.v45i3.63760

\title{
A FORMAÇ̃̃O EM CIÊNCIAS NOS CURSOS DE PEDAGOGIA: ANÁLISE DAS TESES E DISSERTAÇÕES DO PERÍODO DE 2008 A 2018
}

\author{
ClÉRIA MARIA WENDLING \\ VILMAR MaLACARne \\ Universidade Estadual do Oeste do Paraná (Unioeste), Cascavel, Paraná, Brasil
}

\begin{abstract}
Resumo: Este artigo apresenta uma análise da pesquisa na Pós-Graduação stricto sensu do Brasil sobre a formação para o ensino de Ciências no curso de Pedagogia no período de 2008 a 2018. Foi realizado um "estado do conhecimento", com a localização de 20 teses e dissertações catalogadas no banco de dados da Biblioteca Digital de Teses e Dissertações (BDTD). Do corpus analisado emergiram as categorias: pesquisas descritivas e pesquisas com práticas, e as subcategorias práticas prescritivas e práticas com reflexão. As pesquisas são predominantemente descritivas e filiadas a programas da Educação. Os resultados apontam aspectos formativos em relação ao conteúdo disciplinar, características sobre as fontes do conhecimento dos acadêmicos e características históricas do curso.
\end{abstract}

Palavras-chave: Formação de Professores. Ensino de Ciências. Anos Iniciais do Ensino Fundamental. Curso de Pedagogia.

INTRODUÇÃO

Podemos afirmar que a produção de conhecimento sobre a formação de professores no Brasil está se consolidando em qualidade, tradição e quantidade. De modo mais específico, referente à formação dos professores das Ciências da Natureza, a produção foi impulsionada pelo crescimento de Programas de Pós-Graduação em Ensino de Ciências e seu processo de interiorização (RAMOS; SILVA, 2014; ALMEIDA, 2018).

Na educação infantil e nos anos iniciais do ensino fundamental, a disciplina das Ciências da Natureza e suas tecnologias são trabalhadas por professores formados no curso de Pedagogia e as pesquisas sobre sua formação e prática estão tradicionalmente guiadas pelas Ciências da Educação. No entanto, com a consolidação da área de Ensino, percebe-se um interesse sobre o pedagogo, sua formação e sua prática, contribuindo, assim, com a produção de conhecimentos sobre o ensino de Ciências nos anos iniciais do ensino fundamental (FERNANDES, 2009).

Nesse contexto, o presente estudo pretende conhecer a atual situação da produção de conhecimentos em programas de Pós-Graduação em torno da formação inicial de professores para os anos iniciais do ensino fundamental no que se refere aos conteúdos da área de Ciências da Natureza. Dessa forma, apresentamos um "estado do 
conhecimento" (ROMANOWSKI; ENS, 2006) das teses e dissertações defendidas no período de 2008 a 2018.

\section{O CURSO DE PEDAGOGIA E O ENSINO DE CIÊNCIAS}

Ao percorrer a história da profissionalização dos professores no Brasil, desde os processos de recrutamento de civis e militares no período colonial, passando pelas primeiras escolas do Normal de formação para o magistério (TANURI, 2000), até a atual estrutura universitária (ARAÚJO et al., 2020), podemos perceber a atuação estatal no estabelecimento de um sistema educacional cada vez mais universal. Para Romanowski, "A escola foi originada na conjuntura de ideias liberais da revolução francesa, secularizada, e para o acesso por toda a população" (ROMANOWSKI, 2013, p. 479). Para Nóvoa (2017), a importância dessa tarefa gerou uma elevação de prestígio e autonomia dos professores e também a passagem de um controle administrativo para um controle ideológico da profissão por parte do Estado. O processo de dirigir e controlar a profissão passa pela regulamentação e formação desses profissionais.

A organização curricular das escolas foi a base para formação dos professores desde o início da sua institucionalização. Dessa forma, a atribuição dos professores era bem ensinar todas as matérias do primário, demandando uma formação polivalente (CRUZ, 2017).

No cenário dos anos de 1930, houve uma ampliação do primário e modernização do secundário por uma ampliação do sistema (DELLARIBA, 2009). Em 1939 foram criados os cursos de licenciatura e de Pedagogia na Faculdade Nacional de Filosofia, com o objetivo de formar trabalhadores intelectuais técnicos, professores e pesquisadores. No âmbito da formação de professores, passaram a coexistir diferentes modelos. A formação dos professores do primário (correspondente aos anos iniciais do ensino fundamental) era realizada nas Escolas Normais (GATTI, 2011). Os professores do ensino secundário (correspondente aos anos finais do ensino fundamental e o ensino médio) e dos cursos profissionalizantes eram formados na Faculdade Nacional de Filosofia nas Instituições de Ensino Superior, ou seja, nos cursos de Licenciatura e Pedagogia. O currículo dos cursos de Licenciatura e de Pedagogia era constituído por três anos de formação para o bacharelado, acrescido de um ano de curso em didática para a habilitação no magistério. Esse modelo ficou conhecido na historiografia da educação como "modelo $3+1$ " e perdurou por vinte e três anos no Brasil. Apenas em 1969 começa a ser incorporado na legislação nacional possibilidades sutis para a formação dos professores do primário no ensino superior, em particular, no curso de Pedagogia (FIORIN; FERREIRA, 2013).

Nesse período ocorre a inserção dos conteúdos científicos na educação elementar. $\mathrm{O}$ contexto é de pós-guerra e a comunidade científica apontou caminhos para o desenvolvimento econômico e para a disputa pela hegemonia no mundo polarizado. O desenvolvimento da ciência e da tecnologia passa a ser compreendido como fundamental. No polo capitalista, os esforços de financiamento público são direcionados para o desenvolvimento de armas, da medicina e da indústria, sob o mote de promover a paz mundial, o bem estar da população e o desenvolvimento econômico 
(BUSH, 1945). A centralidade do desenvolvimento científico requeria, no entanto, jovens aptos para a produção científica. Por outro lado, o impacto da bomba atômica gerou um movimento de crítica à ciência, com a reivindicação de controle social.

Essa perspectiva fortaleceu a ampliação da educação científica a toda a população. A formação em Ciências passa a ser entendida como um componente para o exercício da cidadania nas sociedades democráticas. Nos termos de DeBoer (2000, p. 586, tradução nossa): "[...] além de precisar de um suprimento adequado de cientistas, matemáticos e engenheiros tecnicamente treinados, a sociedade também precisava de cidadãos altamente qualificados que entendessem o empreendimento científico".

Em 1961 os conteúdos científicos foram introduzidos nos dois últimos anos do ginásio, nacionalmente (BIZZO, 2009), embora houvesse projetos de ensino de ciências desenvolvidos em vários estados do país antes dessa data. Essa inserção ocorre sob influência do movimento internacional e pela defesa interna da formação de "investigadores para impulsionar o progresso da ciência e tecnologia nacionais das quais dependia o país em processo de industrialização" (KRASILCHIK, 2000, p. 86). Com a LDB 5.692/71, os conteúdos de Ciências são estendidos para o ensino primário de maneira a compor o currículo escolar da Educação Básica do país.

As transformações políticas do cenário nacional dos anos 80, "com evidências da vontade coletiva e marcado pela lógica do direito à educação e do dever do Estado em atendê-lo" (JULIÃO, 2016, p. 43), marcam o conteúdo da constituição de 1988. Contudo, apesar de ser determinante no início da discussão sobre a LDB, essa força já não era dominante na finalização e aprovação dessa lei em 1996. A bandeira da formação superior para os professores da educação infantil e dos anos iniciais do ensino fundamental é prevista na LDB 9394/96, porém de modo alternativo ao modelo universitário. Nos primeiros anos de vigência da LDB 9394/96 são criados, predominantemente pela iniciativa privada, os Institutos Superiores de Educação voltados para a formação dos professores e também os controversos Cursos do Normal Superior, direcionados para a formação dos professores da educação infantil e séries iniciais do ensino fundamental (JULIÃO, 2016).

Os cursos do Normal Superior foram extintos pelos Pareceres CNE/CP n॰ 5/2005 e 3/2006, e pela Resolução CNE/CP no 1/2006, que instituíram as Diretrizes Curriculares Nacionais para o curso de Graduação em Pedagogia - licenciatura (DCNPL). A partir daí ficou instituída uma realidade educativa já experimentada em cursos de Pedagogia de muitas universidades públicas que resistiram ao modelo dos anos 90 e se valeram das possibilidades abertas nas habilitações criadas em 1969 (FIORIN; FERREIRA, 2013). Nas DCNPL de 2006, a identidade na docência é atribuída ao egresso do curso de Pedagogia, preferencialmente voltada para os anos iniciais do ensino fundamental (e suas modalidades) e para a educação infantil. No entanto, a formação para as atividades previstas no Art. 64 da LDB 9494/96: "Administração, planejamento, inspeção, supervisão e orientação educacional para a Educação Básica" também ficou contemplada.

Após quase 10 anos da aprovação das DCNPL, entra em vigor o Parecer CNE/CEB № 02/2015 e a Resolução de mesmo número CNE/CEB № 02/2015, aprovados com ampla discussão da comunidade educativa (HYPOLITO, 2019). Destes documentos consideramos especialmente indicadores de uma revisão da compreensão sobre o papel da formação de professores e do papel do Governo Federal presente na política nacional 
dos últimos anos. O documento se refere ao entendimento relacional entre escola e universidade, estabelecendo não apenas a necessidade de estágio supervisionado na forma de prática de ensino, pois atribui à escola uma importante fonte de saber profissional.

Além disso, houve uma compreensão da formação continuada como essencial para a profissionalização docente. Nesse sentido, a formação continuada não é vista como atualização, reciclagem ou correção de lacunas da formação inicial. Ela é componente da profissionalização em uma perspectiva de educação para toda a vida.

Outro destaque é a ênfase no setor público e presencial dado pelo plano de formação de professores. Nesse sentido, são previstas diversas ações de ampliação do Ensino Superior Público para o atendimento de formação de profissionais da educação com ênfase nas áreas em que há maior demanda a partir da criação de um Plano Nacional de Formação de professores. O cenário mais imediato se mostra controverso. Para Hypólito (2019, p. 197), as "novas diretrizes para os cursos de Licenciaturas, aprovadas pelo CNE e que deveriam estar implantadas em todas as universidades, têm sido adiadas e ficado em suspenso, o que leva a crer que novas diretrizes estão sendo pensadas, mas não discutidas".

De fato, a previsão do autor se expressa na resolução CNE/CP no 2, de 20 de dezembro de 2019, publicada em definitivo em 11 de março de 2020. Essa resolução define as Diretrizes Curriculares Nacionais para a Formação Inicial de Professores para a Educação Básica e institui a Base Nacional Comum para a Formação Inicial de Professores da Educação Básica (BNC-Formação). Esse documento apresenta em detalhes as características curriculares desejadas e cuja centralidade está no desenvolvimento de competência e no alinhamento com a Base Nacional Curricular Comum (BNCC) aprovada em 2017, reduzindo em muito a amplitude da formação dos professores. O propósito explícito desse documento coloca a formação dos professores da educação básica como subordinada à realização do currículo estipulado pela BNCC.

Os efeitos desse documento ainda não podem ser visualizados nas teses e dissertações de nosso corpus de análise, no entanto, seria esperado que o documento direcionasse medidas para a superação dos desafios destacados nestas pesquisas nacionais sobre a formação de professores.

\section{CAMINHOS METODOLÓGICOS: ESTADO DO CONHECIMENTO}

Com o objetivo de conhecer as pesquisas realizadas no campo de Ensino de Ciências sobre a formação inicial dos professores que atuam nos anos iniciais do ensino fundamental, realizamos o estudo e análise intitulados "Estado do Conhecimento". O estudo buscou conhecer a produção desenvolvida nos cursos de Pós-Graduação nos últimos 11 anos, analisando as dissertações e teses defendidas e disponíveis no catálogo da Biblioteca Digital de Teses e Dissertações (BDTD).

As pesquisas que analisam o conjunto da produção de conhecimentos sobre determinado tema são pesquisas denominadas "Estado da Arte" ou "Estado do Conhecimento", as quais servem para guiar e conhecer a construção teórica e prática das áreas. Além disso, segundo Romanowski e Ens (2006), este tipo de pesquisa aponta 
lacunas, inovações ou restrições na produção e disseminação de alternativas para solucionar problemas. Para eles há uma diferenciação entre as pesquisas de "Estado da Arte" que abrangem toda a produção científica em torno de determinado tema e as pesquisas de "Estado do Conhecimento" que realizam um levantamento de parte da produção: "O estudo que aborda apenas um setor das publicações sobre o tema estudado vem sendo denominado de 'Estado do Conhecimento'" (ROMANOWSKI; ENS, 2006, p. 40).

O presente trabalho, utilizando a diferenciação proposta acima, é, portanto, um "Estado do Conhecimento", pois o conteúdo analisado é composto apenas por teses e dissertações produzidas no Brasil. A definição desse conteúdo decorre da percepção de que a produção de conhecimento e a realização de pesquisas no âmbito educacional ocorrem fortemente em Instituições de Ensino Superior, com especial concentração nos programas de Pós-Graduação stricto sensu (MALOSSE, 1999). As pesquisas ali produzidas e expressas em teses e dissertações circundam parte significativa da pesquisa realizada no Brasil e seus temas têm grande relevância para indicar a tendência de consolidação de linhas de pesquisa, considerando que a formação de pesquisadores ocorre em concomitância com a realização das pesquisas na Pós-Graduação. Conhecer o estado do conhecimento dessa fatia da produção brasileira permite conhecer o período analisado e as tendências de determinada linha de investigação em crescimento.

O levantamento de dados considerou as teses e dissertações com pesquisas em torno da temática da formação inicial de professores dos anos iniciais do ensino fundamental na área de Ensino de Ciências no período de 2008 a 2018. Utilizamos o sistema de busca da BDTD, com os seguintes descritores de busca: assunto "Formação de professores" em todos os campos; "Ensino de Ciências" em todos os campos; "Anos Iniciais" e "Séries Iniciais" também em todos os campos. A escolha desses descritores de busca tão gerais resultou em muitos trabalhos fora do tema. No entanto, essa estratégia foi necessária em decorrência da inexistência de uma nomenclatura mais específica e amplamente utilizada na área. Gatti (2011) diz que a problemática terminológica é um problema para a área da Educação. Para a autora, o uso dos termos "pedagogia", "didática" e 'prática de ensino" são pouco precisos, trazendo "prejuízo quanto à atribuição de relevância aos seus estudos" (GATTI, 2011, p. 138).

Desse corpus extraímos as seguintes informações em formulário do Google. Filiação institucional; Nome do programa; Nome do autor; Tipo de documento; Ano de defesa; Título; Palavras-chave; Natureza da pesquisa; Instrumentos de coleta de dados; Objetivos da pesquisa indicados no resumo; Resultados indicados no resumo. Dados mais pontuais foram apresentados com contagem de frequência quantitativa. As informações em relação ao contexto de produção das publicações (MORAES; GALIAZZI, 2016) nos permitem conhecer as filiações institucionais das pesquisas. Esses dados são indicadores da distribuição da produção sobre o tema em todo o país e da quantidade de instituições dedicadas ao tema, além de possuírem professores e grupos de pesquisa atuando. Assim, cada trabalho pode ser representante de um grupo e não apenas a pessoa que assinou como autor da pesquisa. Para manter a identificação de cada unidade de análise no texto desconstruído, foi adotada uma codificação dos trabalhos. Esses códigos foram construídos pelas iniciais de "Formação Inicial" acrescidas por dois dígitos referentes ao ano de defesa e uma letra do alfabeto, por exemplo, um trabalho sobre formação inicial defendido em 2018 tem a codificação FI18a. 
Os objetivos, resultados, juntamente com as informações metodológicas, foram submetidos à análise textual discursiva. "O primeiro passo da análise é a desconstrução dos textos e sua unitarização" (MORAES; GALIAZZI, 2016). Das unidades de sentido das teses e dissertações emergem as categorias de análise.

Moraes e Galiazzi (2016, p. 193) entendem que na definição de categorias emergentes pressupõe-se que "[...] o pesquisador exercita um esforço de construir novas teorias a partir de elementos teóricos de seus interlocutores empíricos, manifestados por meio dos textos que analisa". O estabelecimento de categorias emergentes, por ser mais exigente no processo de análise, requer uma descrição mais minuciosa do processo. Segundo Moraes e Galiazzi (2016), as categorias devem ter os seguintes atributos: validade ou pertinência; homogeneidade; amplitude e precisão; exaustividade e exclusividade. Os atributos da validade e pertinência requerem que as categorias sejam adequadas aos objetivos da pesquisa, exigindo que estes objetivos estejam estabelecidos de forma clara, com categorias que permitem a realização da análise desejada. Para que as categorias tenham homogeneidade, os critérios de classificação devem estar bem descritos e definidos. As categorias podem ser gerais e não tão precisas ou de menor amplitude em que geralmente são mais precisas. Em um trabalho, no entanto, é necessário manter uma homogeneidade em relação aos graus de precisão e amplitude. As categorias da pesquisa precisam ser capazes de incluir todos os dados pertinentes da pesquisa, ou seja, serem exaustivas e permitirem a classificação de todo o material coletado. $\mathrm{O}$ último atributo para as categorias é a exclusão mútua. Esse atributo requer que cada elemento unitário seja classificado em apenas uma categoria. Nesse ponto, os autores defendem uma relativização, pois, considerando que em determinados momentos do processo de classificação ocorrem dúvidas insuperáveis, há a necessidade de sobreposições.

A classificação realizada a partir das categorias definidas no processo de análise guia a descrição e a interpretação do objeto de estudo. A categorização é uma parte integrante do processo de teorização desenvolvida durante a análise e a apresentação dos resultados.

\section{APRESENTAÇÃO E DISCUSSÃO DOS DADOS}

Em decorrência da utilização dos descritores mais gerais para diminuir a perda de trabalhos foram encontrados e pré-selecionados 836 títulos de teses e dissertações, dos quais 51 corresponderam à formação de professores. Ao excluir os trabalhos sobre formação continuada, restaram 20 títulos sobre a formação inicial. No quadro 1 apresentamos o resultado do primeiro processo de seleção sob a ressalva de que, neste artigo, analisamos apenas os trabalhos sobre a formação inicial.

O estudo realizado por André et al. (1999) sobre a produção e formação de professores referente à década de 90 assinalou que havia uma frequência maior sobre formação inicial:

Em linhas gerais, o exame das dissertações e teses produzidas na década de 1990 sobre formação de professores revela que a maioria dos estudos se concentra na formação inicial, procurando avaliar os 
WENDLING, C. M.; MALACARNE, V.

cursos que formam os docentes. O curso Normal é o mais estudado. O curso de licenciatura também é alvo de muitas pesquisas, enquanto o curso de pedagogia é pouco investigado (ANDRÉ, et al. 1999, p. 303).

Em nosso estudo, percebe-se que há uma inversão em relação aos dados apontados pelas autoras. A formação continuada tem maior frequência e há apenas um trabalho sobre o curso de magistério.

No quadro 1, apresentamos o conjunto das informações gerais do contexto de produção das pesquisas distribuídas nas categorias Educação (referente aos programas de Educação), Ensino (programas de Ensino), Tese e Dissertações.

QUADRO 1 - Contexto de produção das teses e dissertações sobre formação inicial

\begin{tabular}{|c|c|c|c|c|}
\hline Instituição & Educação & Ensino & Tese & Dissertação \\
\hline FIOCRUZ & & 1 & Fl18c & \\
\hline UFC & 1 & & & FI15h \\
\hline FUN & & 1 & & FI18n \\
\hline UEL & & 1 & & Fl11a \\
\hline UFABC & & 1 & & $\mathrm{Fl18b}$ \\
\hline UFBA & 1 & & & Fl12a \\
\hline UFG & 1 & & & Fl17a \\
\hline UFPE & 1 & & & Fl13b \\
\hline \multirow{2}{*}{ UFRGS } & 1 & & FI14c & \\
\hline & & 1 & & FI17i \\
\hline UFRN & 1 & & & $\mathrm{Fl} 8 \mathrm{~b}$ \\
\hline UFRPE & & 1 & & Fl10a \\
\hline \multirow{2}{*}{ UNB } & & 1 & & $\mathrm{Fl} 14 \mathrm{f}$ \\
\hline & 1 & & & Fl8g \\
\hline
\end{tabular}




\begin{tabular}{|c|c|c|c|c|}
\hline \multirow{2}{*}{ UNESP } & & 1 & Fl17h & \\
\cline { 2 - 5 } & 1 & & & Fl18a \\
\hline UNICAMP & 2 & & Fl13a & Fl8a \\
\hline UNIOESTE & 2 & & & Fl17j, Fl14a \\
\hline Frequência & $12(60 \%)$ & $8(40 \%)$ & $4(20 \%)$ & $16(80 \%)$ \\
\hline
\end{tabular}

Fonte: autoria própria (2020).

A produção das teses e dissertações está pulverizada no país com um ou no máximo dois trabalhos por instituição, portanto não há uma instituição de destaque na temática. O grau da maioria dos trabalhos é de mestrado 16 (80\%) e 4 (20\%) são teses de doutoramento. As teses e dissertações foram produzidas em 14 instituições distribuídas em quatro regiões do país, nomeadamente, Sul, Sudeste, Centro-oeste e Nordeste. Verifica-se que a temática é estudada, com maior frequência, em programas de Educação, com uma tendência de aumento de interesse nos programas de Ensino. No estudo de Fernandes (2009), foi reportado um aumento progressivo de produções sobre o Ensino de Ciências no período posterior a aprovação da LDB 9394/96. Em sua análise, ele não identificou uma causa clara, mas apontou como possível justificativa a "universitarização" (MAUÉS, 2003) da formação dos professores, a aprovação dos Parâmetros Curriculares Nacionais, bem como a criação de novos Programas de PósGraduação na área de Ensino de Ciências.

O aumento na produção verificado pela autora se expressa tenuamente em nossos estudos. Vemos que em 2018 houve três trabalhos defendidos, constituindo um trabalho na área da Educação e dois na área do Ensino. Em 2017 houve quatro defesas, sendo que duas são da área do Ensino e duas na área da Educação. Já em 2014 houve três defesas, duas na área da Educação e uma na área do Ensino. As três defesas de 2008 foram na área da Educação. Não foram encontrados trabalhos defendidos em 2009 e 2016. Nos anos de 2010 e 2011, houve uma defesa em cada ano e as duas foram defendidas na área do Ensino. Nos anos de 2012, 2013 e 2015 houve quatro defesas na área da Educação. Assim, podemos dizer que a criação da área do Ensino não repercutiu em um significativo aumento de produção sobre o curso de Pedagogia em relação ao ensino de Ciências, ou seja, o ensino de Ciências do Ensino Fundamental, ao menos no que se refere à formação inicial dos professores, não parece se afastar da área da Educação. Essa característica se deve ao que Nóvoa sinaliza, no prefácio da obra organizada por Hofstetter e Valente (2017), ao afirmar que há uma configuração particular na realidade educacional brasileira, em dois aspectos. $O$ primeiro se refere à manutenção do termo Pedagogia para designar o que na Europa são as Ciências da Educação. E o segundo ponto é o próprio modelo de formação dos professores dos anos iniciais do ensino fundamental que ocorre no curso de Pedagogia. Essa diferença em relação aos outros países é fundamental para compreender a manutenção do debate 
em torno da formação inicial dos professores desse nível da Educação Básica dentro da área da Educação.

Para conhecer os sentidos do ensino de Ciências nas pesquisas sobre o curso de Pedagogia, analisamos os objetivos e os resultados presentes nos resumos dos trabalhos. A leitura dos resumos foi feita a partir de uma postura analítica, identificando os sentidos a partir dos nossos objetivos e recortando as unidades para análise (MORAES; GALLIAZZI, 2016). Na análise textual discursiva apenas as unidades válidas e pertinentes aos objetivos da pesquisa precisam passar pelo processo de unitarização. No quadro 2 apresentamos as unidades de análise em ordem cronológica.

\begin{tabular}{|c|c|}
\hline Código & Unidades de análice \\
\hline FI18n & $\begin{array}{l}\text { Os pesquisadores desenvolveram atividades no curso Normal sobre o tema da física } \\
\text { da condutividade que resultou, através da verificação com testes e pós-testes, em } \\
\text { evidente apropriação dos conceitos pelos participantes. }\end{array}$ \\
\hline Fl18c & $\begin{array}{l}\text { Analisa uma disciplina de ensino de Ciências (EC) em um curso de Pedagogia. Os } \\
\text { resultados apontam dificuldades em relação à fragmentação disciplinar e } \\
\text { metodológica. }\end{array}$ \\
\hline $\mathrm{FI} 18 \mathrm{~b}$ & $\begin{array}{l}\text { Revisão de teses e dissertações sobre a formação em Astronomia até 2017. Os } \\
\text { resultados indicaram um aumento no interesse pela temática, bem como uma } \\
\text { persistência em relação à insuficiência desse tema nos cursos de Pedagogia. }\end{array}$ \\
\hline FI18a. & $\begin{array}{l}\text { Resgata a história da Didática como disciplina no curso de Pedagogia, no período } \\
\text { de } 1963 \text { a 2005, apresentando documentos, fontes bibliográficas e os aspectos } \\
\text { constituintes da disciplina. }\end{array}$ \\
\hline FI17j & $\begin{array}{l}\text { Avalia a formação inicial do pedagogo para o EC. Aponta como resultado a } \\
\text { contribuição do curso nos aspectos práticos-metodológicos e fragilidades na } \\
\text { formação em relação à aquisição do conhecimento específico, em certa medida, } \\
\text { sobre as concepções de Ciências e de aprendizagem de Ciências. }\end{array}$ \\
\hline FI17i & $\begin{array}{c}\text { A interlocução entre a neurociência, prática e formação docente no curso de } \\
\text { Pedagogia. O estudo evidencia que há na literatura evidências da relevância desses } \\
\text { conhecimentos para a formação dos professores, no entanto, pouco presentes nos } \\
\text { cursos de Pedagogia investigados. }\end{array}$ \\
\hline Fl17h & $\begin{array}{c}\text { É analisado o processo de desenvolvimento dos trabalhos de final de curso em } \\
\text { Pedagogia sobre questões sócio-científicas. O trabalho utiliza as categorias de } \\
\text { semiformação e formação cultural, resultando na identificação de ambas } \\
\text { permeadas por um caminho desafiador para a construção da autonomia, da } \\
\text { criatividade e da valorização da subjetividade. }\end{array}$ \\
\hline $\mathrm{FI17a}$ & $\begin{array}{l}\text { Investigou o estado atual das propostas de formação de pedagogos para o EC em } \\
\text { universidades públicas goianas. A pesquisa concluiu que esses cursos formam } \\
\text { pedagogos com possibilidades de desenvolver um ensino satisfatório de Ciências. }\end{array}$ \\
\hline FI17| & $\begin{array}{l}\text { Estudou o processo de desenvolvimento dos conceitos científicos na criança no } \\
\text { período dos anos iniciais do Ensino Fundamental (EF) e estabeleceu relações com os } \\
\text { currículos de cursos de Pedagogia. Problematização a capacidade plena do } \\
\text { pedagogo para o EC. }\end{array}$ \\
\hline Fl15h & $\begin{array}{l}\text { Descreve e explica a utilização de histórias em quadrinhos (HQ) como didática de } \\
\text { formação inicial de professores. A estratégia formativa se mostrou vantajosa para } \\
\text { ampliação de conceitos científicos e noções preservacionistas. }\end{array}$ \\
\hline
\end{tabular}




\begin{tabular}{|c|c|}
\hline Fl14f & $\begin{array}{l}\text { Conhecer como os professores em formação inicial a distância relacionam os } \\
\text { saberes da experiência com os saberes acessados pelo curso para o ensino de } \\
\text { ecologia. Os resultados apontam que as fontes de conhecimento sobre ecologia } \\
\text { desses sujeitos são a formação básica, a experiência, o livro didático e a internet. }\end{array}$ \\
\hline FI14C & $\begin{array}{l}\text { Analisa dois projetos de curso de Pedagogia e o desenvolvimento do EC nas escolas } \\
\text { durante os estágios da disciplina de metodologia do ensino de Ciências. Evidenciou } \\
\text { que, por intermédio do EC, é possível o desenvolvimento de um pensamento crítico } \\
\text { tanto na formação docente quanto na Educação Básica. }\end{array}$ \\
\hline FI14a & $\begin{array}{l}\text { Objetivou interpretar a formação inicial do pedagogo sobre o EC. Apontou-se que a } \\
\text { formação é frágil e aligeirada devendo-se dar mais atenção a formação dos } \\
\text { formadores, bem como mais tempo para as áreas específicas. }\end{array}$ \\
\hline FI13b & $\begin{array}{l}\text { Objetivou estabelecer possíveis relações entre a formação docente em Pedagogia e } \\
\text { a concepção dos professores sobre o EC nos anos iniciais. Os resultados apontam } \\
\text { relações insuficientes no tocante aos conteúdos conceituais e das estratégias de } \\
\text { ensino e defende aproximação das ementas das disciplinas com os PCNs. }\end{array}$ \\
\hline Fl13a & $\begin{array}{l}\text { Conhecer as fontes de aquisição dos conhecimentos sobre o EC. Os resultados } \\
\text { apontam para fontes como práticas cotidianas, manuais, internet, revistas e o curso } \\
\text { de Pedagogia. Indica a importância de valorização dos cursos de formação } \\
\text { complementar. }\end{array}$ \\
\hline FI12a & $\begin{array}{l}\text { A pesquisa analisou a formação para o EC desenvolvido no curso de Pedagogo. } \\
\text { Aponta que há dependência do saberes pré-profissionais que se mostraram } \\
\text { insuficientes e que comprometem o trabalho no curso. Aponta para a pesquisa } \\
\text { como base formativa para atenuar as lacunas pré-formatavas, bem como influir na } \\
\text { Educação Básica. }\end{array}$ \\
\hline Fl11a & $\begin{array}{l}\text { Desenvolver e avaliar um processo de formação inicial que concilie aspectos } \\
\text { conceituais e metodológicos. Evidenciou a relevância da abordagem para a } \\
\text { compreensão dos conceitos científicos, da metodologia. }\end{array}$ \\
\hline FI10a & $\begin{array}{l}\text { Analisa-se como se efetiva o EC no curso de Pedagogia. O resultado aponta para a } \\
\text { necessidade de disciplinas que tratam de conhecimentos de área metodológica e } \\
\text { específica relativas ao conhecimento científico. }\end{array}$ \\
\hline $\mathrm{Fl} 8 \mathrm{~g}$ & $\begin{array}{l}\text { Investiga a atividade formativa no curso de Pedagogia de produção de literatura } \\
\text { infantil científica para gerar interesse pela Ciência. Aponta que insegurança e } \\
\text { sensação de incapacidade de aprender Ciência são os principais obstáculos a serem } \\
\text { superados pelos pedagogos em formação. Aponta para a revisão de posturas } \\
\text { quanto à própria aprendizagem. }\end{array}$ \\
\hline $\mathrm{Fl} 8 \mathrm{~b}$ & $\begin{array}{l}\text { Investigar as concepções sobre a natureza das Ciências de pedagogas em formação } \\
\text { inicial. Os resultados apontam concepções não satisfatórias com as epistemologias } \\
\text { contemporâneas. }\end{array}$ \\
\hline $\mathrm{Fl} 8 \mathrm{a}$ & $\begin{array}{l}\text { Destrinchar a relação dos estudantes de Pedagogia com o conhecimento sobre as } \\
\text { Ciências Naturais. Essa relação é marcada, segundo os resultados da pesquisa, pela } \\
\text { rejeição e insegurança de modo a requerer atenção nos processos de formação. }\end{array}$ \\
\hline $\mathrm{Fl} 8 \mathrm{c}$ & $\begin{array}{l}\text { Estuda uma proposta de formação inicial de professores pedagogos na disciplina de } \\
\text { Ciências. A proposta didático-metodológica usou a história da Ciência associada às } \\
\text { atividades experimentais envolvendo execução, registro e análise. Os resultados } \\
\text { apontam para a importância dessa abordagem na formação inicial dos professores } \\
\text { dos anos iniciais. }\end{array}$ \\
\hline
\end{tabular}

Fonte: autoria própria (2020). 
WENDLING, C. M.; MALACARNE, V.

A partir da fragmentação dos resumos do corpus em unidades de análise, realizamos o processo de classificação para a compreensão e explicação dos sentidos das pesquisas sobre o ensino de Ciências no curso de Pedagogia. A classificação das pesquisas resultou nas categorias Pesquisas descritivas e Pesquisas com intervenção.

Na categoria Pesquisas descritivas reunimos os trabalhos que investigam as concepções dos professores, a relação das concepções dos professores com o curso de formação, bem como investigações sobre as características dos próprios cursos. Portanto, essa categoria abrange pesquisas sobre as concepções que guiam a organização curricular dos cursos de formação e as concepções dos professores. Essas pesquisas adotam um desenho interpretativo (FERNANDES, 2009) em que os pesquisadores não interferem no objeto em estudo, mas se propõem a descrever, avaliar e interpretar fatores da realidade.

Na categoria Pesquisas com intervenção, classificamos as pesquisas em que os pesquisadores fizeram intervenção no objeto de estudo, também denominadas por Fernandes (2005) pela terminologia "pesquisas de intervenção", ou seja, o pesquisador age em seu contexto de pesquisa. Nessa categoria estão classificados os trabalhos nos quais foram desenvolvidas práticas de formação, tais como cursos de formação, preparação, implementação e avaliação de materiais para subsidiar a formação de professores e transformações nas concepções ou práticas dos professores geradas pela formação desenvolvida.

Os trabalhos da categoria Pesquisas com intervenção foram subdivididos conforme as características das práticas desenvolvidas gerando as subcategorias Práticas prescritivas e Reflexão sobre a prática. A característica principal da subcategoria Práticas prescritivas é a sua verticalidade, ou seja, o pesquisador/formador planeja a intervenção sem a participação do público alvo nas tomadas de decisão sobre os rumos dos cursos. Almeida (2008, p. 112) considera como prescrições as formações em que determinados sujeitos dizem aos professores "o quê, quando e como trabalhar com seus alunos". Portanto, classificamos nessa subcategoria os trabalhos em que foram desenvolvidos processos formativos elaborados pelos pesquisadores e direcionados aos professores e futuros professores em formação. Podem ser de desenvolvimento de materiais a serem utilizados pelos professores em formação, apresentação de cursos, palestras etc.

A subcategoria Reflexão sobre a prática se refere a pesquisas que têm a intencionalidade de produzir melhorias na prática e produzir conhecimento a partir do processo colaborativo e autorreflexivo. Em diversas obras de inserção na pesquisa nacional e internacional, autores (FREIRE, 2001; RAMALHO, et al., 2004; ELIOTT, 2005; IMBERNÓN, 2006; REALI et al., 2008) defendem a perspectiva reflexiva na formação dos professores. São pesquisas do tipo ação-reflexão-ação e, portanto, realizam intervenções formativas de forma colaborativa e de investigação de práticas. O quadro 3 apresenta a classificação dos trabalhos nas respectivas categorias e subcategorias.

QUADRO 3 - Classificação a partir das categorias e subcategorias emergentes

\begin{tabular}{|c|c|c|}
\hline Categorias & Subcategorias & Códigos dos trabalhos \\
\hline
\end{tabular}




\begin{tabular}{|c|c|c|}
\hline \multicolumn{2}{|c|}{ Pesquisas descritivas } & FI18a, FI18c, FI17j, FI17h, FI17i, FI17a, FI14a, FI14c, \\
\hline \multirow{2}{*}{$\begin{array}{l}\text { Pesquisas } \\
\text { com } \\
\text { intervenção }\end{array}$} & Práticas prescritivas & FI18n, FI15h, FI11a, Fl8c. \\
\hline & $\begin{array}{l}\text { Reflexão sobre } \\
\text { práticas }\end{array}$ & Fl8g. \\
\hline
\end{tabular}

Fonte: autoria própria (2020).

$\mathrm{Na}$ categoria Pesquisas descritivas, foram classificadas quinze teses e dissertações que discutem concepções, conhecimentos, saberes e ou competências desenvolvidas em disciplinas e cursos de formação existentes e desenvolvidos por outrem. É a categoria com maior quantidade de trabalhos. Romanowski (2013) apontou essa característica nas teses e dissertações analisadas por diferentes autores. Para a autora:

As pesquisas, geralmente, são diagnósticas do tipo levantamento empíricas analíticas, das quais decorrem como resultados apontamentos da situação, indicando especialmente os conflitos, inconsistências existentes nesses cursos e programas. Inclui a reformulação dos cursos, os conhecimentos abordados nas disciplinas, as práticas e processos, as aprendizagens, concepções, representações de professores e de alunos (ROMANOWSKI, 2013, p. 485).

Os trabalhos dessa categoria apontaram problemas e deficiências persistentes na formação, principalmente em torno dos conhecimentos científicos da área das Ciências Naturais e também, em menor frequência, em torno de conhecimentos epistemológicos. São seis trabalhos que apresentam, como resultado, um diagnóstico negativo em relação ao curso. Termos como insuficiência, insatisfatório, pouco tempo de conteúdo específico, curso frágil e aligeirado qualificaram a problemática do curso de Pedagogia.

Além dos apontamentos, das fragilidades e problemas, há a descrição de possibilidades em relação ao desenvolvimento crítico e autônomo dos estudantes em formação inicial de professores. Os resumos trazem indicações de mudanças a serem implementadas para superação de tais lacunas. Dentre as indicações, estão a inserção ou maior ênfase nos conteúdos científicos, mais quantidade de horas para área e mais qualidade no trabalho desenvolvido. Há, ainda, os estudos que apontam para um diagnóstico de que o curso requer atenção às questões epistemológicas. Outros trabalhos produziram levantamentos históricos dos cursos de formação e avaliações da produção geral sobre a formação de professores, descrevendo a situação da produção de conhecimento sobre o tema.

Na categoria Pesquisas com intervenção foram classificados cinco trabalhos, destes, quatro são de Práticas prescritivas, ou seja, propuseram, implementaram e diagnosticaram os efeitos de propostas de formação desenvolvidos pelos 
investigadores. Analisaram também concepções dos participantes e possíveis mudanças geradas pelas intervenções. São avaliados processos e resultados de intervenções formativas realizadas na formação inicial.

Os resultados buscam ratificar essas práticas como necessárias para a superação das lacunas da formação ao proporcionar aporte teórico, metodológico e de conhecimento de conteúdos aos professores na formação inicial. Achados semelhantes vêm de Pereira (2011), ao apontar que as pesquisas analisadas sobre a formação de professores dos anos iniciais do ensino fundamental apresentavam uma perspectiva prescritiva.

Além disso, a autora apontou que muitos estudos do seu corpus de análise estavam voltados para as metodologias, recursos e temáticas específicas de Ciências e partiam do pressuposto da deficiência na formação dos professores pedagogos. As pesquisas desenvolvidas na área de ensino de Ciências têm contribuído, segundo Almeida (2018, p. 113), para a "superação das prescrições ao professor, ainda que em alguns casos permaneçam as recomendações vazias". Para a autora, mesmo as prescrições não vazias não indicam um caminho único aos professores e pesquisadores.

A terceira subcategoria, Reflexão sobre a prática, foi extraída a partir de um trabalho apenas. A pesquisa aborda a implementação de atividades de formação pautadas pela perspectiva do trabalho coletivo e colaborativo de cunho reflexivo. Os elementos de reflexão sobre a prática foi o eixo formativo desse trabalho. Os resultados descritos nesse resumo apontam para a própria defesa da reflexão sobre a própria prática como importante ferramenta de formação na formação inicial. Segundo Pereira (2011, p. 170), a "especificidade do trabalho docente é afirmada como atividade que pressupõe refletir sobre a ação, o que exige a formação de um professor reflexivo [...]". Os trabalhos com essa abordagem são mais frequentes na formação continuada de professores. No entanto, a formação de professores reflexivos deve ser feita na formação inicial e continuada no processo de desenvolvimento profissional que acompanha toda a vida profissional dos professores.

\section{CONSIDERAÇÕES FINAIS}

As pesquisas produzidas nos programas de Pós-Graduação nos últimos 11 anos revelam perspectivas e sentidos variados sobre o ensino de Ciência na formação de professores desenvolvida no curso de Pedagogia. O quadro de pesquisas sobre formação inicial é composto por pesquisas descritivas sobre as concepções dos sujeitos e instituições, análise de situação e levantamento histórico. Essas pesquisas revelam em seus resultados a percepção de insuficiência, conflitos e inconsistências, principalmente no que tange aos conhecimentos científicos disciplinares. Em sua maioria apresentam sugestões de reformulação curricular e pontos a serem melhor abordados nos cursos, pontos estes relativos à maior ênfase aos conhecimentos científicos. As pesquisas abordaram a disciplina do Ensino de Ciências, atividades de estágio e trabalho de final de curso. Foram encontradas poucas pesquisas com intervenção na formação inicial e estas são, em sua maioria, de natureza prescritiva, de transmissão de conteúdo ou de metodologias específicas. Foi encontrado, entre os trabalhos com intervenção, o estabelecimento de parcerias da universidade com a escola ou com a formação continuada na perspectiva da reflexão sobre a prática. 
Seria importante que houvesse mais pesquisas de intervenção com propostas investigativas de reflexão sobre a prática. As diretrizes de 2015 indicavam uma maior aproximação com a escola em uma perspectiva colaborativa e de investigação sobre a prática. É preocupante que as pesquisas com intervenção ou as pesquisas experimentais sejam pouco implementadas e avaliadas na formação inicial, pois elas possibilitam o desenvolvimento de novas propostas e processos muitas vezes inovadores. A formação inicial precisa de maior atenção, considerando que é esperado que todos os professores dos anos iniciais se formem no curso de Pedagogia. Além disso, tem sido um campo de intensas disputas em torno da definição de seu currículo. Da mesma forma, atividades de formação inicial articuladas com a escola e a formação continuada na perspectiva do desenvolvimento profissional também carecem de mais pesquisas.

Artigo recebido em: 26/06/2020

Aprovado para publicação em: 13/10/2020

\section{TRAINING PORTRAITS FOR THE TEACHING OF SCIENCES OF PRIMARY TEACHERS IN THESES AND} DISSERTATIONS

ABSTRACT: This article presents an analysis of the research in the stricto sensu Graduate Program in Brazil to the Science Teaching in the primary school education from 2008 to 2018. A "state of knowledge" was carried out, by locating 20 theses and dissertations not cataloged in the BDTD database. From the analyzed corpus emerged the categories of descriptive research and research with practices and the subcategories of prescriptive and practical practices with reflection. The surveys are predominantly descriptive and affiliated with Education programs. The results point out formative aspects in relation to the disciplinary content, characteristics about the academic sources of knowledge and historical characteristics of the course.

KEYWORDS: Teacher Training. Science Teaching. Primary Education. Pedagogy Course.

RETRATOS DE FORMACIÓN INICIAL PARA LA ENSEÑANZA DE LAS CIENCIAS DE LOS PROFESORES EN CIENCIAS EN TESES Y DISERTACIONES

RESUMEN: Este artículo presenta un análisis de la investigación en el Programa de Posgrado stricto sensu en Brasil sobre la formación para la enseñanza de las Ciencias en el curso de Pedagogía de 2008 a 2018. Se realizó un "estado de conocimiento", debido a la ubicación de 20 tesis y disertaciones no catalogado en la base de datos BDTD. Del corpus analizado surgieron las categorías de investigación descriptiva e investigación con prácticas y las subcategorías de prácticas prescriptivas y prácticas con reflexión. Las pesquisas son predominantemente descriptivas y están afiliadas a programas de educación. Los resultados señalan aspectos formativos en relación al contenido disciplinar, características sobre las fuentes académicas de conocimiento y características históricas del curso

Inter-Ação, Goiânia, v.46, n.1, p. 166-182, jan./mar. 2021. Disponível em: <http://dx.doi.org/10.5216/ia.v45i3.63760>. 
WENDLING, C. M.; MALACARNE, V.

PALABRAS CLAVE: Formación Docente. Enseñanza de las Ciencias. Educación Primaria. Curso de Pedagogía.

\section{REFERÊNCIAS}

ALMEIDA, M. J. P. M. Pesquisas no Ensino de Ciências no Brasil, algumas questões representações e convergências. Ciências em Foco, v. 11, n. 1, p. 108-116, 2018.

ANDRÉ, M. SIMÕES, R. H. S; CARVALHO, J. M.; BRZEZINSKI, I. Estado da arte da formação de professores no Brasil. Educação \& Sociedade, v. 20, n. 68, p. 301-309, 1999.

ARAÚJO, D. S.; BRZEZINSK, I.; SÁ, H. G. M. Políticas públicas para formação de professores: entre conquistas, retrocessos e resistências. Revista de Educação Pública, v. 29, p. 1-26, 2020.

BRASIL. Conselho Nacional de Educação, Resolução CNE/CP nº 02/2015 de 2 de junho de 2015. Diretrizes Curriculares Nacionais para a formação inicial em nível superior (cursos de licenciatura, cursos de formação pedagógica para graduados e cursos de segunda licenciatura) e para a formação continuada. Brasília, DF: Diário Oficial da União, 2 jun. 2015.

BRASIL, Conselho Nacional de Educação, Resolução CNE/CP n 02/2019 de 20 de dezembro de 2019. Diretrizes Curriculares Nacionais para a Formação Inicial de Professores para a Educação Básica e institui a Base Nacional Comum para a Formação Inicial de Professores da Educação Básica (BNC-Formação). Brasília, DF: Diário Oficial da União. 10 fev. 2020. [Versão corrigida].

BUSH, V. Science, the endless frontier. Massachusetts: Marine Biological Laboratory Library, 1945.

DALLARIBA, N.. A reforma Francisco Campos e a modernização nacionalizada do ensino secundário. Educação, v. 32, n. 2, p. 185-191, 2009.

FERNANDES, R. C. A. Tendências da pesquisa acadêmica sobre o ensino de ciências nas séries iniciais da escolarização (1972-2005). 2009. 161f. Dissertação (Mestrado em Educação) - Universidade Estadual de Campinas/SP, 2009.

FIORIN, B. P. A; FERREIRA, L. S. O Curso de Pedagogia no Brasil: história e influência para o trabalho dos pedagogos. Revista Reflexão e Ação, v. 21, n. Número especial, p. 44-65, 2013.

GATTI, B. Reflexões sobre questões metodológicas e práticas em pesquisa em Educação. In: GARCIA, W. Textos selecionados de Bernadette Gatti. Belo Horizonte: Autêntica Editora, p. 133-159, 2011. 
HYPOLITO, A. M. BNCC, Agenda Global e Formação Docente. Retratos da Escola, v. 13, n. 25, p. 187-201, 2019.

JULIÃO, V. R. P. O Curso Normal Superior do Instituto Superior de Educação De Garça e Aspectos da História da Formação de Professores no Brasil (2003-2007). 2016. 211 f. Dissertação (Mestrado em Educação) - Universidade Estadual Paulista, Marília, 2016.

KRASILCHIK, M. Reformas e realidade: o caso do ensino das ciências. São Paulo em Perspectiva, v. 14, n. 1, p. 85-93, 2000.

MORAES, R.; GALIAZZI, M. C. Análise textual discursiva. 3a. ed. ljuí: Unijuí, 2016.

PEREIRA, T. V. Discursos que produzem sentidos sobre o ensino de ciências nos anos iniciais de escolaridade. Educação em Revista, v. 27, n. 2, p. 151-176, 2011.

NÓVOA, A. Firmar a posição como professor, afirmar a profissão docente. Cadernos de Pesquisa, v. 47, n. 166, p. 1106-1133, 2017.

RAMOS, C. R.; SILVA, J. A. A emergência da área de Ensino de Ciências e Matemática da Capes enquanto comunidade científica: um estudo documental. Investigações em Ensino de Ciências, v. 19, n. 2, p. 363-380, 2014.

ROMANOWSKI, J. P. Tendências da pesquisa em formação de professores. Atos de Pesquisa em Educação, v. 8, n. 2, p. 479-499, 2013

ROMANOWSKI, J. P.; ENS, R. T. As pesquisas denominadas do tipo "estado da arte" em educação. Revista Diálogo Educacional, v. 6, n. 19, p. 37-50, 2006.

SEVERO, J. L. R. L. Formação e profissionalidade docente: a pedagogia como base. Revista Reflexão e Ação, v. 24, n. 2, p. 261-279, 2016.

TANURI, L. M. História da formação de professores. Revista Educação Brasileira, n. 14, p. 61-88, 2000.

TARDIF, M. Saberes profissionais dos professores e conhecimentos universitários: Elementos para uma epistemologia da prática em relação à formação para o magistério. Revista Brasileira de Educação, n. 13, p. 5-24, 2000.

VILELA-RIBEIRO, E. B.; BENITE, A. M. C. A crise de eficiência da escola para além de seus muros: a influência dos capitais social, cultural e econômico no desempenho escolar em ciências. Ciência \& Educação (Bauru), v. 23, n. 2, p. 403-418, 2017. 
WENDLING, C. M.; MALACARNE, V.

Cléria Maria Wendling: Possui graduação em Pedagogia pela Universidade Federal de Santa Maria (2001) e mestrado em Educação pela Universidade Federal de Santa Maria (2004). Professor assistente da Universidade Estadual do Oeste do Paraná do curso de Pedagogia nas disciplinas Teoria e prática do ensino de ciências e estágio supervisionado sob forma de prática de ensino. Tem experiência na área de Educação, com ênfase em Currículos Específicos para Níveis e Tipos de Educação, atuando principalmente nos seguintes temas: formação de professores, Ensino de Ciências, prática educativa, investigação-ação educacional. Atualmente cursa doutorado no PPGECEM na Unioeste, campus de Cascavel, investigando os sentidos do ensino de ciências no município de Toledo, Paraná.

Orcid: https://orcid.org/0000-0001-5021-7679

E-mail: cleriamwe@gmail.com

Vilmar Malacarne: Possui graduação em Filosofia Licenciatura Plena pela Universidade Federal de Santa Maria (1994), mestrado em Educação pela Universidade Federal de Santa Maria (1997) e doutorado em Educação pela Universidade de São Paulo (2007). Atualmente é professor Associado da Universidade Estadual do Oeste do Paraná. Atua na graduação e na pós-graduação Lato e Stricto Sensu. Tem experiência na área de Filosofia e Ensino de Ciências, atuando principalmente nos seguintes temas: Formação de Professores, Ética, Ciência e Religião.

Orcid: https://orcid.org/0000-0002-5222-4722

E-mail:vilmar.malacarne@unioeste.br

Este periódico utiliza a licença Creative Commons Attribution 3.0, para periódicos de acesso aberto (Open Archives Iniciative - OAI). 